\title{
BREVE REFLEXIÓN SOBRE LA NECESIDAD DE PRESENTAR INDICIOS SUFICIENTES DE CARENCIA DE RAZONABILIDAD EN EL PROCEDIMIENTO DE ELIMINACIÓN DE BARRERAS BUROCRÁTICAS
}

\section{BRIEF REFLECTION ON THE NEED TO SUBMIT SUFFICIENT SIGNS OF FAILURE OF REASONABILITY IN THE PROCEDURE OF ELIMINATION OF BUREAUCRATIC BARRIERS}

\author{
Ayrton Guzmán Chuquillanqui \\ Abogado \\ Universidad de San Martín de Porres \\ asgchuquillanqui@gmail.com \\ Perú, Lima
}

\section{SUMARIO}

- Pasado y presente.

- Origen de la metodología de análisis para los procedimientos de eliminación de barreras burocráticas y de la obligación de presentar indicios suficientes de carencia de razonabilidad.

- Noción de razonabilidad en el Perú.

- La obligación de ofrecer indicios suficientes de razonabilidad es innecesaria.

- Conclusiones.

\section{RESUMEN}

En el presente trabajo hemos querido exponer, brevemente, algunas reflexiones acerca de la relevancia de presentar indicios suficientes de carencia de razonabilidad en los procedimientos de eliminación de barreras burocráticas, desde un enfoque más principista que técnico, invitando al lector a preguntarse si este requerimiento resulta necesario a la luz de los derechos que tiene todo denunciante en un procedimiento administrativo.

\section{ABSTRACT}

In the present work we wanted to briefly present some reflections about the relevance of presenting sufficient evidence of lack of reasonableness in the procedures to eliminate bureaucratic barriers, from a more principlist than a technical approach, inviting the reader to ask if this requirement is necessary in light of the rights that every complainant has in an administrative proceeding.

\section{PALABRAS CLAVE}

Barreras burocráticas; INDECOPI; procedimiento administrativo.

\section{KEYWORDS}

Bureaucratic barriers; INDECOPI; administrative Procedure.

\section{PASADO Y PRESENTE}

Una de las secuencias más celebradas y recordadas de Risas y Salsa, memorable programa cómico de los sábados por la noche, era la de El doctor Chantada. En dicho sketch, además del vozarrón inconfundible de Álex Valle, se parodiaban todas las peripecias que sobrellevaban los administrados de la época (hablamos de la década de los ochenta), para poder echar a andar un proyecto empresarial. Por ejemplo, cierto día se presentó en la municipalidad un caballero que se decía ser experto en belleza, de apariencia poco esbelta y algo tosca (nos referimos a Guillermo Campos, a quien siempre fastidiaban por su poco agraciado semblante), que quería obtener una licencia para abrir un instituto paradójicamente dedicado a la belleza, razón por la cual acudió al despacho de "el inspector municipal", personaje encarnado por Álex Valle. Así, luego de una breve y graciosa discusión de lo conveniente del negocio, el inspector municipal detalló cuáles eran los requisitos que debía 
cumplir el administrado, para abrir su instituto: en cuanto a su persona, título profesional de maquillador, certificado de buena conducta expedido por la Policía de Investigación del Perú (la PIP) y, asimismo, un certificado de salud; con respecto al establecimiento en donde se iba a prestar la atención, este debía estar enchapado con mayólicas hasta el techo, sus baños debían contar con toallitas especiales, calefacción, agua fría y caliente, y, por último, un guardapolvos para el personal operativo, con la particularidad de que todos aquellos implementos debían ser adquiridos de la propia comuna. Frente a ello, como era lógico, el administrado cuestionó por qué debía comprar todos aquellos bienes del mismo municipio, más aún cuando él ya tenía todo instalado y listo para funcionar. La respuesta del funcionario fue clara y categórica: “ $¡ E s a s$ son disposiciones, señor!". Felizmente, gracias a la providencial mediación de "el tramitador", suerte de burócrata con talento para "ayudar" a los administrados en sus procedimientos engorrosos, caracterizado por Antonio Salim, el experto en belleza, luego de realizar algunos pagos adicionales, pudo obtener su licencia y marchar más tranquilo a su casa; en tanto que el inspector, cómodamente ubicado en su trono de servidor público $\mathrm{y}$ acariciando su prominente barriga, cuando el tramitador ya se había retirado a seguir ayudando a más entrampados vecinos, se regocijaba por haber ayudado al prójimo en su problema, eso sí, decía él, "dentro de la ley y la justicia".

Este episodio grafica con notable acierto el escenario al que los administrados se enfrentaban hace más de cuarenta años cuando pretendían iniciar un negocio, en donde, además de asumir los gastos típicos que demanda toda actividad lucrativa, debían soportar los requerimientos, excesos, cuándo no el mal trato, de una clase de servidores destinada a enraizarse en las siempre frágiles bases del Estado: la burocracia.

Piénsese en el Estado no como un ente abstracto, sino, por el contrario, como un individuo común y corriente, que avanza con lentitud hacia un destino incierto, y cuyos brazos sostienen una pesada canasta provista de bienes esenciales para toda una sociedad. Piénsese que al lado de aquel individuo aparece un hombre que le pregunta si puede echarle una mano, y a quien el señor Estado, aunque muy agradecido, le responde que no; que metros más adelante surge otro hombre que también le expresa su deseo de ayudarlo a llevar su carga, pero quien igualmente es rechazado. Y que, a lo largo del camino, el cual paulatinamente se vuelve más peligroso, aparecen una y otra vez personajes dispuestos a prestarle su apoyo, quienes, lamentablemente, corren la misma suerte que los dos primeros individuos. Piénsese que, a pesar de haber sido desairados, todos los hombres acompañan en conjunto el paso del reacio y acaparador andante, como un séquito a la expectativa de alguna voz de auxilio. Ahora bien, piénsese que todos, al ver que el señor Estado se aproxima a un fango profundo, se detienen; que desisten en manifestarle su apoyo $\mathrm{y}$, en silencio, lo dejan alejarse con mucha más dificultad hacia un terreno inhóspito; y lo ven sumergirse lentamente en una sábana gris y espesa, perder el equilibrio y caer de manera estrepitosa, desparramando todos sus bienes esenciales en el lodo, que ya no podrán ser llevados a toda la sociedad.

Ocurre que, en efecto, el Estado carece de capacidad para poder atender con eficiencia todas las demandas de una sociedad: no puede llevar solitariamente la pesada canasta que contiene la salud pública, la seguridad ciudadana, la educación, los servicios públicos, la administración de justicia, así como otro tipo de necesidades secundarias, sin que ello no implique grandes riesgos en su implementación, como sería, por ejemplo, la ausencia de incentivos para una óptima prestación de un servicio público o la ineficiente asignación de recursos para una obra, así como la baja calidad de los bienes producidos y la siempre latente corrupción. Y si a ello añadimos una burocracia (el fango de nuestro ejemplo) que, en lugar de cooperar, entorpece la rápida marcha de aquel ser orgánico llamado Estado, y que desincentiva a quienes buscan aligerar su pesada carga ejerciendo una administración ineficiente a causa del papeleo, la rigidez y las formalidades superfluas ${ }^{1}$, no es difícil imaginar que la tarea de aquel solitario caminante resulta ciertamente inviable. Necesita, pues, servirse de la ayuda de otros personajes ajenos a la Administración Pública. Ello no quiere decir, sin embargo, que se deba desposeer al Estado de sus tareas esenciales, sino simple y llanamente volverlo menos intervencionista.

Así, con el objetivo de otorgar un régimen de estabilidad jurídica a los inversionistas

\footnotetext{
1 Cuarta acepción de la palabra burocracia según el Diccionario
} de la Real Academia de la Lengua Española. 
de razonabilidad en el procedimiento de eliminación de barreras burocráticas

Brief reflection on the need to submit sufficient signs of failure of reasonability

in the procedure of elimination of bureaucratic barriers

extranjeros y crear condiciones más favorables para la inversión privada en los diferentes sectores productivos, a principios de los años noventa se aprobaron los Decretos Legislativos $\mathrm{N}^{\circ} 662$ y 757 respectivamente. Por medio de estos dispositivos legales se establecieron principios y directrices orientadas a garantizar la libre iniciativa privada y las inversiones nacionales y extranjeras, efectuadas o por efectuarse, en todos los sectores de la actividad económica y en cualesquiera de las formas empresariales o contractuales permitidas por la Constitución Política y las leyes. Al respecto, cabe precisar que en aquel momento aún se encontraba vigente la Constitución Política de 1979, que, si bien por primera vez consagraba en su Artículo $115^{\circ}$ que la iniciativa privada era libre y se ejercía en una economía social de mercado, le permitía al Estado realizar actividad empresarial con el fin de promover la economía del país, prestar servicios públicos y alcanzar los objetivos de desarrollo; no obstante, una vez aprobada la Constitución Política de 1993, de acuerdo con su Artículo $58^{\circ 2}$, el Estado pasó de ser un planificador y ordenador de la política económica a ser un garante de derechos y libertades (rol subsidiario del Estado), encargado de supervisar y castigar aquellas actuaciones que vayan en contra de la libre competencia, inclusive las que podrían originarse de la propia Administración Pública, como es el caso de las barreras burocráticas, esto es, aquellos cobros, requisitos, exigencias, prohibiciones o limitaciones impuestas por una autoridad en el ejercicio de función administrativa, que obstaculizan el acceso y la permanencia de los agentes económicos en el mercado o contravienen principios y derechos vinculados a la simplificación administrativa.

\section{ORIGEN DE LA METODOLOGÍA DE ANÁLISIS PARA LOS PROCEDIMIENTOS DE ELIMINACIÓN DE BARRERAS BUROCRÁTICAS Y DE LA OBLIGACIÓN DE PRESENTAR INDICIOS SUFICIENTES DE CARENCIA DE RAZONABILIDAD}

Siendo necesario que existiera una institución encargada de vigilar el correcto funcionamiento

2 Artículo $58^{\circ}$. - La iniciativa privada es libre. Se ejerce en una economía social de mercado. Bajo este régimen, el Estado orienta el desarrollo del pais, y actúa principalmente en las áreas de promoción de empleo, salud, educación, seguridad, servicios públicos e infraestructura. del sistema económico, mediante Decreto Ley $\mathrm{N}^{\circ} 25868$, se creó el Instituto Nacional de Defensa de la Competencia y de la Propiedad Intelectual - INDECOPI, entidad compuesta por comisiones y salas especializadas en propiedad intelectual, defensa de la competencia, protección al consumidor, procedimientos concursales y, recientemente, eliminación de barreras burocráticas. Así, uno de los órganos de esta novedosa institución fue la Comisión de Acceso y Salida del Mercado, que tiempo después, a raíz de los cambios promovidos por el Decreto Legislativo $\mathrm{N}^{\circ} 807$ - Ley sobre Facultades, Normas y Organización del INDECOPI, pasaría a llamarse Comisión de Acceso al Mercado, hasta adoptar la actual nomenclatura de Comisión de Eliminación de Barreras Burocráticas; órgano competente para conocer sobre los actos y disposiciones de las entidades de la Administración Pública, incluso del ámbito municipal o regional, que impongan ilegal o irracionalmente barreras burocráticas en perjuicio de los agentes económicos en el mercado, a través de un procedimiento administrativo de eliminación de barreras burocráticas. Al respecto, Maraví (2013) señala, acertadamente, que este procedimiento otorgó a los administrados una vía para que puedan cuestionar las actuaciones arbitrarias de las autoridades.

En ese contexto, en agosto de 1997, cuando las entidades de la Administración Pública no asumían un rol institucional en la eliminación de trabas, sobrecostos y restricciones a la inversión privada, el Tribunal del INDECOPI de aquel entonces aprobó un precedente de observancia obligatoria sumamente importante en la historia de esta materia, que, además de establecer una metodología de análisis respecto de la legalidad y carencia de razonabilidad de una barrera, impondría al denunciante un papel mucho más activo en el procedimiento: la obligación de presentar indicios suficientes sobre la carencia de razonabilidad.

En efecto, mediante la Resolución $\mathrm{N}^{\circ}$ 1821997-TDC, conocido también como el precedente taxis amarillos (en adelante, el Precedente), se estableció una metodología de análisis para examinar toda barrera burocrática que llegara a conocimiento de la Comisión de Acceso al Mercado ${ }^{3}$ o del Tribunal. Dicha

3 Todavía no se la denomina Comisión de Eliminación de Barreras Burocráticas 
metodología consistía, por un lado, en realizar un análisis de legalidad en donde se evaluaba si la medida encuadraba o no dentro de las competencias y atribuciones conferidas a la entidad administrativa, y si para su emisión se habían respetado los procedimientos y formalidades previstos expresamente en la ley; por otro lado, si la medida superaba aquel primer análisis y el denunciante había cumplido con ofrecer elementos de juicio razonables que demostraban tratamientos discriminatorios, arbitrariedad o desproporción, esto es, indicios de la existencia de una barrera irracional, se procedía a requerirle a la entidad denunciada que acreditara la racionalidad de la medida, y se realizaba un análisis de razonabilidad en el cual la comisión o el Tribunal verificaban si se encontraba justificada por un interés público; si las cargas o restricciones impuestas eran o no proporcionales a los fines que se quería alcanzar; y si existían, o no, otras opciones para lograr el mismo objetivo con menores costos, es decir, la medida menos gravosa entre una serie de opciones que la autoridad -en teoríahabía considerado como posibles soluciones a un determinado problema de interés público.

Esta metodología fue empleada por el INDECOPI en todos los procedimientos en donde se denunciaba la ilegalidad o carencia de razonabilidad de una presunta barrera burocrática, cuya estructura originaria, pese a los ligeros cambios impuestos por el Decreto Legislativo $\mathrm{N}^{\circ} 1256$ - Ley de Prevención y Eliminación de Barreras Burocráticas, se ha mantenido hasta nuestros días. Así, de conformidad con los Artículos $16^{4}$ y 20 , inciso $6^{5}$ de la citada ley, todos los administrados

4 Articulo 16.- Indicios sobre la carencia de razonabilidad

16.1 Los indicios a los que hace referencia el artículo precedente deben estar dirigidos a sustentar que la barrera burocrática califica en alguno de los siguientes supuestos:

a. Medina arbitraria: es una medida que carece de fundamentos y/o justificación, o que teniendo una justificación no resulta adecuada o idónea para alcanzar el objetivo de la medida; y/o

b. Medida desproporcionada: es una medida que resulta excesiva en relación con sus fines y/o respecto de la cual existe otra u otras medidas alternativas que puedan lograr el mismo objetivo de manera menos gravosa.

16.2 Sin que se considere como una lista taxativa, no se consideran indicios suficientes para realizar el análisis de razonabilidad los siguientes argumentos:

a. Que no se encuentren referidos a la barrera burocrática cuestionada.

b. Que tengan como finalidad cuestionar la pertinencia de una politica pública.

c. Alegaciones o afirmaciones genéricas. Se deben justificar las razones por las cuales se considera que la medida es arbitraria y/o desproporcionada.

d. Alegar como único argumento que la medida genera costos.

5 Articulo 20.- Requisitos para interponer una denuncia que denuncien la carencia de razonabilidad de un determinado cobro, requisito, exigencia, prohibición o limitación en los términos de su Artículo $3^{\circ}$, Inciso $3^{\text {o6 }}$, además de los habituales fundamentos de hecho y de derecho, necesariamente deberán presentar indicios suficientes que demuestren la arbitrariedad y desproporción de la barrera; ello, sin embargo, no implica que automáticamente la comisión o el Tribunal procederán con el análisis de razonabilidad, en la medida que los indicios serán evaluados por el órgano resolutivo correspondiente, que bien podría considerar que tales indicios no resultan suficientes para entrar a analizar la carencia de razonabilidad. Así, el procedimiento de eliminación de barreras adquiere cierta dialéctica, como José Enrique Sotomayor Trelles (2017) lo sostiene:

Para interponer una denuncia, además del pago de la respectiva tasa, el denunciante debe identificar de manera concisa y/o presentar a través de su denuncia o anexos, los siguientes aspectos:

1. La(s) barrera(s) burocrática(s) materia de denuncia

2. El medio de materialización: disposición administrativa, acto administrativo y/o actuación material. En caso de denunciar una disposición administrativa, el denunciante además debe identificar el párrafo, el artículo o parte pertinente en que se encuentra materializada la barrera burocrática.

3. La entidad (o entidades) que impone(n) y/o aplica(n) barrera(s) burocrática(s) materia de denuncia.

4. Los hechos, cuando la barrera burocrática se materializa en actos administrativos y/o actuaciones materiales.

5. Los fundamentos juridicos que sustentan que la barrera burocrática denunciaba es ilegal, de ser el caso.

6. Los indicios que sustentan la presunta carencia de razonabilidad de la barrera burocrática denunciada, de ser el caso.

7. La(s) barrera(s) burocrática(s) materia de denuncia.

8. El medio de materialización: disposición administrativa, acto administrativo y/o actuación material. En caso de denunciar una disposición administrativa, el denunciante además debe identificar el párrafo, el artículo o parte pertinente en que se encuentra materializada la barrera burocrática.

9. La entidad (o entidades) que impone(n) y/o aplica(n) la(s) burocrática(s) materia de denuncia

10. Los hechos, cuando la barrera burocrática se materializa en actos administrativos y/o actuaciones materiales.

11. Los fundamentos jurídicos que sustentan que la barrera burocrática denunciada es ilegal, de ser el caso.

12. Los indicios que sustentan la presunta carencia de razonabilidad de la barrera burocrática denunciada, de ser el caso.

6 Artículo 3.- Definiciones para efectos de la presente ley, debe tenerse encuentra las siguientes definiciones: 1. La Comisión: La Comisión de Eliminación de Barreras Burocráticas del INDECOPI. Asimismo, este término se refiere a las Comisiones adscritas a las oficinas regionales del INDECOPI que, por acuerdo del Consejo Directivo del INDECOPI, cuenten con funciones desconcentradas en materia de eliminación de barreras burocráticas. (...)

3. Barrera burocrática: exigencia, requisito, limitación, prohibición $\mathrm{y} / \mathrm{o}$ cobro que imponga cualquier entidad, dirigido a condicionar, restringir u obstaculizar, el acceso y/o permanencia de los agentes económicos en el mercado y/o que puedan afectar a administrados en la tramitación de procedimientos administrativo sujetos a las normas y/o cobro no implica necesariamente su carácter ilegal y/o su carencia de razonabilidad. 
Lo que resulta interesante (...) es que en la metodología de Indecopi (i) se incorpora a las partes como actores activos en el proceso de toma de decisiones, con lo cual el mismo se torna dialéctico, y (ii) se establecen reglas de carga de la prueba que permiten que, en determinadas instancias del procedimiento, la prueba sobre los elementos empíricos para una adecuada toma de decisiones recaiga sobre cada una de las partes, bajo un escrutinio argumentativo por parte de Indecopi. (Página 71).

Pues bien, esta condición de aportar indicios suficientes respecto de la carencia de razonabilidad de una barrera burocrática, en la medida que, internamente, no ha sido objeto de cuestionamiento por los interesados en la materia $^{7}$ y se ha aceptado como una condición sine qua non para el análisis de razonabilidad, merece de nuestra parte una breve reflexión acerca de su necesidad.

Para tal efecto, con el objetivo de resaltar la importancia de la razonabilidad en todo proceso o procedimiento, pasaremos a desarrollar cómo se ha concebido a este principio general del derecho en nuestro país.

\section{NOCIÓN DE RAZONABILIDAD EN EL PERÚ}

Si bien en el Artículo $200^{\circ}$ de la Constitución Política del Perú se consagra que, al interponerse acciones de habeas corpus y amparos en relación con derechos restringidos y suspendidos durante regímenes de excepción (estados de emergencia y de sitio), el órgano jurisdiccional debe examinar la razonabilidad y la proporcionalidad del acto restrictivo (aquel que restrinja o suspenda la libertad y la seguridad personales, la inviolabilidad del domicilio, y la libertad de reunión y de tránsito), no cabe duda de que los alcances de estos principios no se agotan en el escenario de los procesos constitucionales, sino que, por el contrario, se extienden a todos los ámbitos del derecho en donde los ciudadanos se vean perjudicados por actuaciones del Estado,

7 La mayoría de autores, o por lo menos a los que hemos podido tener acceso, que le han dedicado importantes páginas al estudio del mecanismo de eliminación de barreras burocráticas en el Perú, se han enfocado en analizar su constitucionalidad, sus efectos positivos en las actividades económicas, lo interesante que resulta su metodología, sin avocarse a cuestionar la carga probatoria que se le impone al denunciante/administrado en el procedimiento. provengan estas del legislativo, del ejecutivo, o de cualquier órgano de gobierno regional o local.

Así, en el Artículo IV, Inciso $1^{\circ}$, Numeral 1.4 del Título Preliminar del Decreto Supremo $\mathrm{N}^{\circ}$ 006-2017 - T.U.O. de la Ley No 27444 - Ley del Procedimiento Administrativo General (en adelante, la Ley del Procedimiento Administrativo General $)^{8}$, el legislador peruano ha regulado al principio de razonabilidad en los siguientes términos:

1.4. Principio de razonabilidad. - Las decisiones de la autoridad administrativa, cuando creen obligaciones, califiquen infracciones, impongan sanciones, o establezcan restricciones a los administrados, deben adaptarse dentro de los límites de la facultad atribuida y manteniendo la debida proporción entre los medios a emplear y los fines públicos que deba tutelar, a fin de que respondan a lo estrictamente necesario para la satisfacción de su cometido. (Subrayado agregado).

Como vemos, el legislador, pese a que en el Numeral 1.4 enuncia al principio de razonabilidad, probablemente porque en la práctica legislativa ha sido el término más empleado al momento de regular los límites de los actos discrecionales del Estado, ha determinado sus alcances a partir del contenido material de otro principio, del cual ya se hizo mención: el de proporcionalidad. De manera que, de acuerdo con la Ley del Procedimiento Administrativo General, en virtud a la razonabilidad, las autoridades deben procurar que sus actuaciones guarden proporción entre los medios que emplea y los fines públicos que tutela.

Esta noción, pues, se ha extendido a los medios de ejecución forzosa ${ }^{9}$, al ámbito de los procedimientos administrativos sancionadores ${ }^{10} \mathrm{y}$ de manera muy particular

8 Publicada el 20 de marzo de 2017 en el Diario Oficial El Peruano.

9 Artículo 205.- Medios de ejecución forzosa. -

205.1 La ejecución forzosa por la entidad se efectuará respetando siempre el principio de razonabilidad, por los siguientes medios:

a) Ejecución coactiva

b) Ejecución subsidiaria

c) Multa coercitiva

d) Compulsión sobre las personas

10 Artículo 246.- Principios de la potestad sancionadora administrativa. - 
al proceso de cuantificación de las multas impuestas a concesionarias de servicios públicos, en el caso de infracciones administrativas que tengan como fundamento el incumplimiento de la realización de trámites, obtención de licencias, permisos y autorizaciones, estableciéndose que las multas no pueden exceder del $1 \%$ del valor de la obra o proyecto, o del $100 \%$ de la tasa aplicable por derecho de trámite, de acuerdo al Texto Único de Procedimientos Administrativos (TUPA) de la entidad.

Por otro lado, la Ley № 29158 - Ley Orgánica del Poder Ejecutivo11, en el Artículo II de su Título Preliminar, regula el principio de servicio al ciudadano, en virtud del cual las entidades del Poder Ejecutivo están al servicio de las personas y de la sociedad; actúan en función de sus necesidades, así como del interés general de la nación, asegurando que su actividad se realice, entre otros aspectos, con arreglo al criterio de la simplicidad (Inciso $3^{\circ}$ del Artículo II de la ley), que implica la eliminación de todo requisito y procedimiento innecesario, y que los procesos deban ser racionales y proporcionales a los fines que se persigue. Así, a diferencia de la proporción entre medios y fines, en esta ley la razonabilidad se manifiesta en la manera cómo las entidades estructuran sus procedimientos, que, desde luego, deben garantizar que los derechos e intereses de los ciudadanos no sean afectados por la exigencia de aspectos formales innecesarios.

En cuanto a la Ley $\mathrm{N}^{\circ} 27972$ - Ley Orgánica de Municipalidades ${ }^{12}$, el Artículo $38^{\circ}$ señala que las normas y disposiciones municipales

\footnotetext{
La potestad sancionadora de todas las entidades está regida adicionalmente por los siguientes principios especiales: (...)

3. Razonabilidad. - Las autoridades deben prever que la comisión de la conducta sancionable no resulte más ventajosa para el infractor que cumplir con las normas infringidas o asumir la sanción. Sin embargo, las sanciones a ser aplicadas deben ser proporcionales al incumplimiento calificado como infractor, observando los siguientes criterios que se señalan a efectos de su graduación:

a) El beneficio ilicito resultante por la comisión de la infracción;

b) La probabilidad de detección de la infracción;

c) La gravedad del daño al interés público y/o bien jurídico protegido;

d) El perjuicio económico causado;

e) La reincidencia, por la comisión de la misma infracción dentro del plazo de un (1) año desde que quedó firme la resolución que sancionó la primera infracción;

f) Las circunstancias de la comisión de la infracción; y

g) La existencia o no de intencionalidad en la conducta del infractor.

11 Publicada el 20 de diciembre de 2007 en el Diario Oficial El Peruano.

12 Publicada el 27 de mayo de 2003 en el Diario Oficial El Peruano.
}

se rigen por los principios de exclusividad, territorialidad, legalidad y simplificación administrativa, sin perjuicio de la vigencia de otros principios generales del derecho administrativo, lo que, en consecuencia, vincula a todos los principios taxativamente regulados en la Ley del Procedimiento Administrativo General, como, por ejemplo, el de razonabilidad. Así, algunas disposiciones emitidas por gobiernos locales, como la Ordenanza $\mathrm{N}^{\circ} 485-\mathrm{MDS}^{13}$ y la Ordenanza $\mathrm{N}^{\circ}$ 205-MDA ${ }^{14}$, han recogido expresamente a este principio, y otras lo han hecho bajo la fórmula de una norma de remisión, que invoca en un solo artículo a todos los principios de manera general y los integra a la ordenanza respectiva ${ }^{15}$.

Por otra parte, Morón (2017), acerca del principio de razonabilidad y su vinculación con el de proporcionalidad, sostiene que existe una similitud entre ambos principios, en la medida que una decisión que se adopta en el marco de convergencias de dos principios constitucionales, cuando no respeta el principio de proporcionalidad, no será razonable. De manera que el principio de razonabilidad sugiere una valoración respecto del resultado del razonamiento del juzgador expresado en su

13 Artículo $3^{\circ}$ Principios de la Potestad Sancionadora Administrativa

La potestad sancionadora está regida por los siguientes principios especiales contenidos en el artículo $230^{\circ}$ de la Ley $\mathrm{N}^{\circ} 27444$ :

(...)

3. Razonabilidad. - Las autoridades deben prever que la comisión de la conducta sancionable no resulte más ventajosa para el infractor que cumplir las normas infringidas o asumir la sanción; así como que la determinación de la sanción considere criterios como la existencia o no de intencionalidad, el perjuicio causado, las circunstancias de la comisión de la infracción y la repetición en la comisión de infracción. Artículo I.- Potestad sancionadora de la Municipalidad Distrital de Santa Anita.

La potestad sancionadora de la Municipalidad de Santa Anita, se encuentra reconocida en la Ley Orgánica de MunicipalidadesLey $\mathrm{N}^{\circ} 27972$, que implica la tipificación de las conductas constitutivas de infracción, la fiscalización, la instauración del proceso administrativo sancionador y eventualmente la aplicación de sanciones ante el incumplimiento de las disposiciones municipales.

El procedimiento sancionador que regula la presente Ordenanza, se rige por los principios especiales, establecidos en el artículo $\mathrm{N}^{\circ} 230$ de la Ley del Procedimiento Administrativo General $\mathrm{N}^{\circ}$ 27444, asi como aquellos artículos correspondientes al (...) procedimiento administrativo sancionador.

3. Razonabilidad. - Las autoridades deben prever que la comisión de la conducta sancionable no resulte más ventajosa para el infractor que cumplir las normas infringidas o asumir la sanción; así como que la determinación de la sanción considere criterios como la existencia o no de intencionalidad, el perjuicio causado, las circunstancias de la comisión de la infracción y la repetición en la comisión de infracción.

15 Léase la Resolución $N^{\circ}$ 1879-2017-TCE-S4 y la Resolución $\mathrm{N}^{\circ}$ 2427-2017-TCE-S3 emitidas por el Tribunal de Contrataciones del Estado. 
Brief reflection on the need to submit sufficient signs of failure of reasonability in the procedure of elimination of bureaucratic barriers

decisión, en tanto que el procedimiento para arribar a este resultado sería la aplicación del principio de proporcionalidad.

Ahora bien, a nivel de la jurisprudencia administrativa, el Tribunal de Contrataciones del Estado emplea el principio de razonabilidad como un criterio para la graduación de las sanciones, por ejemplo, en los casos en que los proveedores presenten documentos falsos o adulterados a las entidades, al Tribunal de Contrataciones del Estado o al Registro Nacional de Proveedores ${ }^{16}$, tomando en cuenta aspectos como la naturaleza de la infracción; la ausencia de intencionalidad del infractor; la inexistencia o grado mínimo de daño causado a la Entidad; el reconocimiento de la infracción antes que sea detectada; los antecedentes de sanción o sanciones por el Tribunal; la conducta procesal, y la adopción e implementación del modelo de prevención a que se refiere el Artículo $50^{\circ}$, Numeral 50.7 de la Ley $\mathrm{N}^{\circ} 30225$ - Ley de Contrataciones del Estado.

Sin embargo, es el Tribunal Constitucional quien mayores luces ha dado sobre este principio a nivel jurisprudencial. Así, como señala Castillo (2005), en un primer momento el Tribunal consideró que, por el principio de razonabilidad, una medida restrictiva de derechos debía estar justificada en la necesidad de preservar, proteger o promover un fin constitucionalmente válido, de manera que la razonabilidad quedaría justificada por la persecución de un fin legítimo y, además, de rango constitucional; diferenciándolo, así, del principio de proporcionalidad, que exigía el cumplimiento de los sub criterios de idoneidad, necesidad $\mathrm{y}$ proporcionalidad en sentido estricto. En otro momento, sin embargo, el Tribunal señaló que, más allá de la convención doctrinaria que admite su autonomía como concepto, en puridad, la proporcionalidad era sólo una modalidad más de la razonabilidad ${ }^{17}$; y, finalmente, como lo explica Burga (2011), el Tribunal terminó por integrar la razonabilidad en el principio de proporcionalidad, indicando que el primero estaba comprendido como un presupuesto del segundo.

No obstante, todo lo desarrollado hasta este punto, es necesario señalar que, si bien los

16 Léase la Resolución $N^{\circ}$ 1879-2017-TCE-S4 y la Resolución $\mathrm{N}^{\circ}$ 2427-2017-TCE-S3 emitidas por el Tribunal de Contrataciones del Estado.

17 Sentencia del Tribunal Constitucional de fecha 04 de julio de 2004 - Expediente $\mathrm{N}^{\circ}$ 0090-2004-AA/TC. principios de razonabilidad y proporcionalidad son por antonomasia contrarios a la arbitrariedad del Estado, es este último principio el que ha tenido una notable trascendencia desde sus orígenes en la jurisprudencia alemana. Así, el principio de proporcionalidad, cuya noción, como señala Hartwig (2010), se aplicaba ya en la jurisdicción administrativa alemana antes de la Primera Guerra Mundial, encuentra su fundamento en la cláusula del Estado de Derecho, previsto en el Artículo 28.1 de la Ley Fundamental de la República Federal Alemana, y en los derechos fundamentales de la persona, otorgándole, así, rango constitucional.

Sobre este aspecto, Luis Castillo-Córdova (2005) señala:

No hay duda que el Estado de derecho fundamenta el principio de proporcionalidad en la medida que, al sujetarse el poder político a la Constitución, se sujeta también a los dispositivos constitucionales que reconocen $y$ garantizan derechos, sujeción que le obliga a un respeto irrestricto de los mismos y, en todo caso, a que la afectación de los derechos sea razonable y equilibrada, es decir, se ajuste a las exigencias del principio de proporcionalidad. (Página 6)

Pues bien, de todolodesarrollado anteriormente, es preciso destacar que la razonabilidad y la proporcionalidad, como principios generales de jerarquía constitucional, ciertamente cumplen un papel importante en la protección de los ciudadanos frente a los excesos del Estado.

De manera que, precisamente en atención a esta importancia, su aplicación en un procedimiento administrativo, como el de eliminación de barreras burocráticas, no puede estar sujeta a condición alguna, menos aún si ella podría resultar innecesaria, como veremos a continuación.

\section{LA OBLIGACIÓN DE OFRECER INDICIOS SUFICIENTES DE RAZONABILIDAD ES INNECESARIA}

Los indicios, según Carrión (2000), son actos, circunstancias, vestigios y en general cualquier hecho que sirve de base para conocer o inferir otro hecho desconocido. Así, en el 
procedimiento de eliminación de barreras burocráticas, los denunciantes se encuentran obligados a presentar indicios que demuestren la arbitrariedad y/o desproporción de una medida, siempre que cuestionen su carencia de razonabilidad. De suerte que el derecho de los denunciantes a obtener una decisión sobre la razonabilidad de una barrera parecería reducirse, en nuestro país, a una especie de intercambio con efectos impredecibles, que podría resumirse de la siguiente manera: Si tú me das indicios, yo te doy razonabilidad. Ello, sin embargo, nos parece una carga innecesaria, ya que quien debería demostrar si un cobro, requisito, exigencia, prohibición o limitación no es arbitraria ni desproporcionada es la misma entidad que creó la barrera, de manera que única y exclusivamente sea ella quien ofrezca los elementos de juicio que permitan un correcto análisis de razonabilidad.

Como bien señala Jorge (2011), el derecho administrativo tiene sentido mientras sirva para la defensa de los administrados y su acceso a la justicia, y en tanto garantice la vigencia del principio de legalidad y de los valores del Estado de Derecho, siendo muchas veces el juicio de razonabilidad el último remedio para purgar las decisiones arbitrarias de los poderes públicos que afectan a los administrados. Por ello, la carga de demostrar que las barreras impuestas a través de actos, disposiciones o cualquier otra actuación administrativa no son arbitrarias ni desproporcionadas, como condición para acceder al análisis de razonabilidad, debería recaer únicamente en la Administración Pública, ya que es quien se encuentra en una mejor capacidad de aportar los elementos necesarios para realizar un sólido análisis; además, "la carga de la prueba impuesta a los denunciantes para cuestionar la carencia de razonabilidad de un acto o disposición administrativa es elevada, pues debe estar debidamente motivada para crear convicción en los comisionados de la CEB o en los vocales de la Sala" (Ugás Sobarzo y Paredes Fiestas 2014, página 91).

Por ello, y recordando el principio de servicio al ciudadano, previsto en el Artículo II del Título Preliminar de la Ley $\mathrm{N}^{\circ} 29158$ - Ley Orgánica del Poder Ejecutivo, siendo el INDECOPI una entidad cuya tarea consiste en acoger las denuncias de los administrados, quienes se ven atrapados en ese fango que desincentiva sus iniciativas de inversión o que simple y llanamente no simplifica sus trámites particulares, no debería, en virtud a un innecesario formalismo, limitarles la posibilidad de analizar la carencia de razonabilidad de una barrera presuntamente arbitraria, menos aún si ello implica sacrificar principios básicos que garantizan la legalidad de todo procedimiento administrativo, así como desviar la finalidad del mismo: eliminar la barrera burocrática.

Al respecto, Allan Brewer Carías (2011), con mucho acierto, señala lo siguiente:

El procedimiento administrativo, por ello, nunca puede considerarse como un fin en sí mismo, sino como un instrumento o cauce para alcanzar el fin perseguido por la administración. De allí que el llamado principio de instrumentalidad de las leyes de procedimiento, el cual permite desdoblar la finalidad del procedimiento administrativo en tres: primero, la consecución del interés general; segundo, la satisfacción del interés del administrado; y tercero, el logro del interés de la propia administración sometida a la legalidad. (Página 52)

Esto encuentra sentido en el hecho que quienes acuden al INDECOPI, para denunciar la ilegalidad y/o carencia de razonabilidad de una barrera, tienen como propósito natural que la entidad no les siga imponiendo la barrera, esgrimiendo, para tal efecto, los argumentos de hecho y de derecho que sustentan su pedido. Así, si entendemos que es deber de las autoridades en el procedimiento actuar dentro del ámbito de su competencia y conforme a los fines para los que les fueron conferidas sus atribuciones, 19 no debería ser el objeto del procedimiento que al denunciante, de seguro extenuado por la incómoda experiencia de padecer los estragos de la tramitología estatal, se le adicione la carga (nuevamente del Estado) de demostrar la arbitrariedad y/o desproporción de una barrera, sino procurar que la medida sea sometida a los dos niveles de análisis, sin excepción, y que se verifique su legalidad o carencia de razonabilidad. Ello, desde luego, sin perder de vista cuál es el interés del administrado en el procedimiento, de acuerdo con el principio de informalismo, previsto en el Artículo IV, Inciso $1^{\circ}$, Numeral 1.6 de la Ley del Procedimiento Administrativo General en los siguientes términos: 
Brief reflection on the need to submit sufficient signs of failure of reasonability in the procedure of elimination of bureaucratic barriers

Principio de informalismo. - Las normas de procedimiento deben ser interpretadas en forma favorable a la admisión y decisión final de las pretensiones de los administrados, de modo que sus derechos e intereses no sean afectados por la exigencia de aspectos formales que puedan ser subsanados dentro del procedimiento, siempre que dicha excusa no afecte derechos de terceros o el interés público.

Este principio "se orienta a proteger a los particulares a efectos de que no se vean perjudicados por cuestiones meramente procesales, relativizándose las exigencias adjetivas" (Ivanega 2011, página 165), cuyo contenido, como señala Guzmán (2009), nos permite afirmar que lo más importante es que lo sustantivo prevalezca sobre las formas. En ese orden de ideas, Morante (2015) señala que existen cuatro elementos que deben converger para que sea procedente la aplicación del principio de informalismo, que a continuación enumeramos: (1) El elemento subjetivo; (2) el elemento de forma; (3) el elemento de cumplimiento futuro y (4) el elemento de no afectación. Acto seguido, pasaremos a analizar cada uno de ellos tomando como referencia al procedimiento de eliminación de barreras burocráticas.

\section{El elemento subjetivo}

El sujeto que puede invocar el principio de informalismo en el procedimiento, para defender sus derechos e intereses, es siempre el administrado. De manera que son los ciudadanos quienes ostentan legitimidad para hacer uso de este principio, mas no la Administración Pública, "la cual se encuentra en la obligación de cumplir y respetar cabalmente todas y cada una de las normas y reglas del procedimiento" (Morante 2015, II-2). Por ello, si bien en un procedimiento trilateral -como el procedimiento de eliminación de barreras burocráticas- la Administración Pública tiene la condición de parte ello no le permite invocar la flexibilidad de las formas no esenciales del procedimiento; pues, por principio de legalidad, las autoridades administrativas deben actuar con respeto a la Constitución, la ley y al derecho, dentro de las facultades que le estén atribuidas y de acuerdo con los fines para los que les fueron conferidas. En ese orden de ideas, como señala Mujica (2015), sería ilegítimo que las entidades se amparen en la dispensa de formas para dejar de cumplir con las exigencias que el orden jurídico les impone a sus actuaciones, o para dejar de cumplir con las reglas del procedimiento.

\section{El elemento de forma}

Como sabemos, se entiende por procedimiento administrativo al conjunto de actos y diligencias tramitados en las entidades, conducentes a la emisión de un acto administrativo que produzca efectos jurídicos individuales $\mathrm{o}$ individualizables sobre intereses, obligaciones o derechos de los administrados. Así, este segundo elemento hace referencia a los aspectos formales que pueden ser subsanados en el desarrollo del procedimiento (no esenciales); que se diferencian de aquellos que no pueden ser subsanados por ser aspectos formales esenciales.

Ahora bien, como señala Ivanega (2011), si las formas no esenciales son aquellas que no están ligadas o no son exigidas por el orden público administrativo, en el procedimiento de eliminación de barreras existe un serio problema; ya que los Artículos $16^{\circ}$ y $20^{\circ}$, Inciso $6^{\circ}$ del Decreto Legislativo $\mathrm{N}^{\circ} 1256-$ Ley de Prevención y Eliminación de Barreras Burocráticas, regulan conjunta y expresamente la obligación de presentar indicios suficientes para acceder al análisis de razonabilidad. De manera que si entendemos que el orden público administrativo comprende tanto a los principios como a las disposiciones previstas en la ley (en su sentido amplio), el requerimiento de presentar indicios suficientes sería una formalidad esencial y, por tanto, no le sería aplicable el principio de informalismo. Sin embargo, precisamente el objeto de este trabajo es llevar a la reflexión si esta condición es realmente necesaria y si aún merece ser recogida en la ley, a la luz de las garantías que importa un análisis de razonabilidad para el administrado frente a los excesos de la Administración Pública.

\section{El elemento de cumplimiento futuro}

Este tercer elemento se refiere a la posibilidad de que la forma no esencial pueda ser subsanada en el desarrollo del procedimiento. Así, por ejemplo, si asumiéramos que la condición de presentar indicios no es una formalidad esencial y que su importancia radica en demostrar la 
arbitrariedad o desproporción de una medida, siendo la entidad que impuso la barrera quien se encuentra en una mejor posición y capacidad de aportar los elementos de juicio idóneos, tranquilamente, al momento de presentar sus descargos o antes de que se emita la decisión del órgano resolutivo, la autoridad denunciada podría presentar al INDECOPI toda aquella información que considere vital para probar la razonabilidad de su medida, de manera que la carga de la prueba se invertiría a favor de los denunciantes y le permitiría al INDECOPI realizar un adecuado análisis de razonabilidad. Ello, desde luego, asumiendo de antemano que dicho análisis no está sujeto a ninguna condición.

\section{El elemento de no afectación}

Finalmente, este cuarto elemento implica que el principio de informalismo no puede ser empleado cuando ello suponga una afectación a los derechos de terceros o al interés público. En cuanto al derecho de terceros, en la medida que la condición de presentar indicios únicamente le es impuesta al denunciante y lo que se pretende es que ella ya no se le exija, la aplicación del principio no afectaría derecho alguno de terceros; y en cuanto al interés público, el permitirle a los administrados obtener una decisión que se pronuncie sobre la razonabilidad de una barrera sin condición alguna, claramente beneficiaría a los administrados y contribuiría con la finalidad del Decreto Legislativo $\mathrm{N}^{\circ}$ 1256 - Ley de Prevención y Eliminación de Barreras Burocráticas, ya que el INDECOPI supervisaría el cumplimiento del marco legal que protege los derechos a la libre iniciativa privada y la libertad de empresa, mediante la eliminación de barreras burocráticas ilegales y/o carentes de razonabilidad que restrinjan u obstaculicen el acceso o la permanencia de los agentes económicos en el mercado y/o que constituyan incumplimientos de las normas y/o principios que garantizan la simplificación administrativa, con el objeto de procurar una eficiente prestación de servicios al ciudadano por parte de las entidades de la Administración Pública.

Por ello, no debemos olvidar que el principio de informalismo se consagra "como una regla de interpretación, orientada a la admisión de las pretensiones, lo cual refleja el contenido del principio pro actione de raigambre constitucional, así como de tutela de derechos e intereses subjetivos, los que claro está no tendrían que verse afectados por la inobservancia de formas" (Mujica 2015, página 75).

Ahora bien, teniendo nuestro derecho administrativo y constitucional una clara influencia española, es preciso mencionar que, por ejemplo, en España, de acuerdo con el Artículo 5.4 de la Ley 03/2013, de 4 de junio, la Comisión Nacional de los Mercados y la Competencia está legitimada para impugnar ante la jurisdicción competente los actos sujetos al derecho administrativo y disposiciones generales de rango inferior a la ley de los que se deriven obstáculos al mantenimiento de una competencia efectiva en los mercados (legitimidad activa). Así, dicha comisión puede impugnar cualquier acto o disposición infralegal que configure un obstáculo para el acceso de un agente económico en el mercado, que contravenga, por ejemplo, el principio de necesidad y proporcionalidad de las actuaciones de las autoridades competentes, regulado en el Artículo $5^{\circ}$ de la Ley 20/2013, de 9 de diciembre, de Garantía de la Unidad de Mercado, de la siguiente manera:

Artículo 5. Principio de necesidad y proporcionalidad de las actuaciones de las autoridades competentes.

1. Las autoridades competentes que en el ejercicio de sus respectivas competencias establezcan límites al acceso a una actividad económica o su ejercicio de conformidad con lo previsto en el artículo 17 de esta Ley o exijan el cumplimiento de requisitos para el desarrollo de una actividad, motivarán su necesidad en la salvaguarda de alguna razón imperiosa de interés general de entre las comprendidas en el artículo 3.11 de la Ley 17/2009, de 23 de noviembre, sobre el libre acceso a las actividades de servicios y su ejercicio.

2. Cualquier límite o requisito establecido conforme al apartado anterior, deberá ser proporcionado a la razón imperiosa de interés general invocada, y habrá de ser tal que no exista otro medio menos restrictivo o distorsionador para la actividad económica.

Así, la proporcionalidad sirve de criterio a la Comisión Nacional de los Mercados y la 
Competencia, para interponer demandas ante los órganos jurisdiccionales respecto de actos y disposiciones infralegales que obstaculicen el acceso de los agentes económicos en el mercado, con el objetivo de que sean removidas del ordenamiento jurídico, claro está, sin que sea necesario que los administrados presenten indicios suficientes de arbitrariedad o de algún trato desproporcionado, ya que el principio de necesidad y proporcionalidad de las actuaciones de las autoridades competentes, taxativamente previsto en el Artículo $5^{\circ}$ de la Ley 20/2013, es un principio inherente al valor justicia y se opone frontalmente a la arbitrariedad en el ejercicio de los poderes públicos, de cuya interdicción hace referencia el Artículo $9^{\circ}$, Inciso $3^{\circ}$ de la Constitución Española, en los siguientes términos:

3. La Constitución garantiza el principio de legalidad, la jerarquía normativa, la publicidad de las normas, la irretroactividad de las disposiciones sancionadoras no favorables o restrictivas de derechos individuales, la seguridad jurídica, la responsabilidad y la interdicción de la arbitrariedad de los poderes públicos.

Por todas estas reflexiones, es preciso preguntarse si la condición de aportar indicios suficientes respecto de la carencia de razonabilidad de una barrera burocrática, teniendo en cuenta la importancia que tiene la razonabilidad frente a los excesos de las diversas entidades del Estado, contribuye a garantizar los derechos de todo administrado en el procedimiento administrativo, y a cumplir con la finalidad del Decreto Legislativo $\mathrm{N}^{\circ}$ 1256 - Ley de Prevención y Eliminación de Barreras Burocráticas.

\section{CONCLUSIONES}

Los principios de razonabilidad y proporcionalidad son principios generales de jerarquía constitucional en nuestro país, cuyos alcances no se agotan en los procesos constitucionales, sino que, por el contrario, se extienden a todos los ámbitos del derecho, como el administrativo; y cumplen un papel sumamente importante en la protección de los ciudadanos frente a los excesos del Estado.

A sabiendas de la importancia que tiene la razonabilidad, no se debería condicionar la posibilidad de que el INDECOPI pudiera emitir una decisión analizando la razonabilidad de una barrera, sino procurar que la medida sea sometida a los dos niveles de análisis, sin excepciones ni limitaciones, y contribuir con la finalidad del procedimiento: eliminar la barrera burocrática.

Porúltimo, la carga de demostrar que las barreras impuestas a través de actos, disposiciones o cualquier otra actuación administrativa no son arbitrarias ni desproporcionadas, como condición para acceder al análisis de razonabilidad, debería recaer únicamente en la entidad que impuso la barrera, ya que es la Administración Pública quien se encuentra en una mejor posición y capacidad de aportar los elementos necesarios, para realizar un sólido análisis de razonabilidad.

\section{FUENTES DE INFORMACIÓN}

\section{Fuentes bibliográficas}

Carrión Lugo, Jorge. (2000). Tratado de derecho procesal civil. Tomo II. Lima, Perú: Editora GRIJLEY.

Hartwig, Matthias. (2010). La 'Proporcionalidad' en la Jurisprudencia del Tribunal Constitucional Federal de Alemania. En Eduardo Ferrer Mac-Gregor $\mathrm{y}$ otros (Coord), La justicia constitucional y su internacionalización ¿Hacia un ius constitucionale commune en América Latina? (781-791), Tomo I. México, México: Universidad Nacional Autónoma de México.

Maraví Sumar, Milagros. (2013). Análisis de las funciones del Indecopi a la luz de las decisiones de sus órganos resolutivos. Lima, Perú: Corporación Gráfica Aliaga SAC.

Morón Urbina, Juan Carlos. (2017). Comentarios a la Ley del Procedimiento Administrativo General - Texto Único Ordenado de la Ley $N^{\circ} 27444$. Tomo II. 12 Edición. Lima, Perú: Imprenta Editorial El Búho E.I.R.L.

\section{Fuentes hemerográficas}

Brewer-Carías, Allan. (2011). La Regulación del procedimiento administrativo en América Latina con ocasión de la primera década (2001-2011) de la Ley del Procedimiento Administrativo General del Perú (ley 27444). En Derecho PUCP. N ${ }^{\circ}$ 67. Páginas 47-76. 
Burga Coronel, Angélica María. (2011). El test de ponderación o proporcionalidad de los derechos fundamentales en la jurisprudencia del Tribunal Constitucional peruano. En Gaceta Constitucional, N $N^{\circ}$ 47. Páginas 253267.

Castillo-Córdova, Luis (2005). El principio de proporcionalidad en la jurisprudencia del Tribunal Constitucional peruano. En Revista Peruana de Derecho Público, Volumen 6 (11). Páginas 127-151.

Guzmán Napurí, Christian. (2009). Los principios generales del derecho administrativo. En Revista Iut Et Veritas, № 38. Páginas 228249 ,

Ivanega, Miriam. (2011). El principio del informalismo en el procedimiento administrativo. En Revista Derecho PUCP. $\mathrm{N}^{\circ}$ 67. Páginas 155-176.

Jorge Coviello, Pedro José (2011). El Principio de proporcionalidad en el procedimiento administrativo. En Revista Derecho PUCP. $\mathrm{N}^{\circ}$ 67. Páginas 139-153.

Morante Guerrero, Luis Eduardo. (2015). La flexibilidad de los procedimientos administrativos como pauta para la modernización: el principio de informalismo. En Actualidad Gubernamental, $\mathrm{N}^{\circ} 77$.

Mujica Acurio, Héctor. (2015). El principio de informalismo. En Ius Et Tribunalis Año 1, N. ${ }^{\circ}$ 1. Páginas 73-85.

Sotomayor Trelles, José Enrique (2017). El test de ponderación como unexamen multicriterio: un análisis a partir de tres modelos ponderativos. En Revista Derecho y Sociedad. $\mathrm{N}^{\circ}$ 48. Página 63-77.

Ugás Sobarzo, Sofía y Paredes Fiestas, Guilliana. (2014) El análisis de razonabilidad a través de los pronunciamientos del Indecopi: cómo evitar medidas impuestas utilizando el De tinmarin de do pingüe. En Revista de la Competencia y la Propiedad Intelectual. Año $10, \mathrm{~N}^{\circ} 19$ (primavera, 2014). Páginas 79-105.

\section{Fuentes legales}

Congreso Constituyente Democrático (1993). Constitución Política de la República. Diario Oficial El Peruano. Lima, 30 de diciembre de 1993.

Presidencia de la República (1991). Ley de promoción de las inversiones extranjeras. Decreto Legislativo 662. Diario Oficial El Peruano. Lima.

Presidencia de la República (1991). Dictan Ley Marco para el crecimiento de la Inversión Privada. Decreto Legislativo 757. En Diario Oficial El Peruano.ç

Presidencia de la República (2016). Decreto Legislativo que aprueba la Ley de Prevención y Eliminación de Barreras Burocráticas. Decreto Legislativo 1256. En Diario Oficial El Peruano.

Presidencia de la República (1992). Ley de Organización y Funciones del Instituto Nacional de Defensa de la Competencia y de la Protección de la Propiedad Intelectual INDECOPI. Decreto Ley 25868. En Diario Oficial El Peruano.

Presidencia de la República (1996). Ley sobre facultades, normas y organización del INDECOPI. Decreto Legislativo 807. En Diario Oficial El Peruano.

Presidencia de la República (2017). Decreto Supremo que aprueba el Texto Único Ordenado de la Ley $\mathrm{N}^{\circ} 27444$ - Ley del Procedimiento Administrativo General. Decreto Supremo 006-2017-JUS. En Diario Oficial El Peruano.

Congreso de la República (2003). Ley Orgánica de Municipalidades. Ley N ${ }^{\circ} 27972$. En Diario Oficial El Peruano.

Congreso de la República (2014). Ley de Contrataciones del Estado. Ley $\mathrm{N}^{\circ} 30225$. En Diario Oficial El Peruano.

\section{Jurisprudencia}

INDECOPI (1997). Resolución $\mathrm{N}^{\circ}$ 1821997-TDC. Recuperado de: https://www. indecopi.gob.pe/documents/20182/168195/ ResolucionN182-97-TDC.pdf/26bc6bb31349-40dc-924c-b2a40825b0e2 